Revista Herencia Vol. 27 (1 y 2), 69-76, 2014

Recibido 12-03-2014 Aprobado 09-04-2014

\title{
Pink Floyd Y SU IMPORTANCIA CULTURAL: un tríptico
}

\begin{abstract}
Resumen
El presente artículo expone, de manera pseudotestimonial, algunas de las que se pueden considerar las razones por las cuales la música de Pink Floyd tiene un valor cultural. Además se exponen y se analizan grosso modo algunos de los temas más significantes del trabajo de la banda en tres de sus álbumes.
\end{abstract}

Palabras claves: Pink Floyd, Cultura.

\section{Abstract}

This article shows, through a testimony-like narration, some of the reasons why the music of Pink Floyd is believed to have a cultural significance. Furthermore, the essay presents the analysis of some of the most remarkable themes in three albums of the band.

Keywords: Pink Floyd, Culture.

David Boza

Méndez.

Músico y escritor. Profesor

de lengua en cursos de

conversación de la Universidad

de Costa Rica. Actualmente,

finalizando el proyecto de graduación de la Maestría en

Literatura Inglesa en la Universidad de Costa Rica. Odia esnobismos y formalidades...

y hablar bien de sí mismo. boza.braindamage@ gmail.com

\section{Palabras iniciales. La experiencia vital}

El primer recuerdo que tengo de haber escuchado Pink Floyd fue entre los $8 \mathrm{y}$ los 9 años. En aquellas épocas, mi casa era mi campo de batalla, selva inexplorada y mi universo, un lugar aún desconocido. Una de las tantas veces en las que corría sin atadura alguna por sus estancias, me detuve en las afueras del cuarto de mi hermano mayor mientras él estudiaba para un examen de farmacia. Lo que entonces me sedujo para hacer una pausa vital fue una melodía que escuché y que por entonces consideré como de otros mundos. La canción, "Terminal Frost", de una banda completamente desconocida para mí, pero que con su sonido ambiental, sus multifacéticos instrumentos y pasajes musicales soberbios me causó una impresión todavía difícil de entender veinte años después.

Tres años más tarde y después de haber estado en contacto con la música de Joaquín Sabina, Bob Marley, Iron Maiden y Queen entre otros, recuerdo que, antes de cualquier evaluación, tenía la costumbre de estudiar escuchando música. Le robaba el guodman a mi hermano y lo que escuchaba era The Wall de 
Pink Floyd. ¿Sabía inglés? Para nada. Sin embargo, la música, los loops, y las voces dulces y desgarradoras de este álbum rebotaban en cada rincón de mi alma. Pero a los 12 años los niños son muy crueles.

Una vez, en medio de un recreo, yo caminaba mientras tarareaba una melodía de dicho álbum. Un compañero me escuchó y gritó "¡David está cantando la canción de Mr. Gadget!" (serie infantil de moda en la época) yo respondí: "¡No!". Inmediatamente después me vi rodeado de un círculo de compañeros señalándome y riéndose porque, ante sus oídos, cantaba el tema de Mr. Gadget y no el violento y sin sentido reggae panameño que se empezaba a escuchar en las radios ticas a finales de los años noventa. Fui víctima de un mezquino bullying, tal cual Steven Dedalus aceptando y luego negando la costumbre de dar un beso de buenas noches a su madre antes de dormir.

Varios años después, me encontré sumido en una situación similar. Una profesora de inglés del colegio nos dejó como trabajo extraclase presentar una canción que nos gustara, había que darle una copia de la letra a cada compañero y explicar el porqué de la fascinación. Después de suficiente consideración, decidí llevar y presentar "High Hopes" de Floyd, una joya de canción, la cual se encuentra en la última producción de la banda. No voy a mentir negando que, para esa época, mi escogencia estaba más que fuera de la mesa de lo que era cool, ya que bandas de corte skato eran las preferidas en esas temporadas (bandas tipo Lim Bisquit, Korn o Blin guan eiri tu). Como era de esperarse, las reacciones de mis compañeros no se hicieron esperar: "mae que es esa música de iglesia"... "qué canción más aburrida" o "mae, Boza, su música nada que ver"... fueron varios de los comentarios "postescénicos" que recibí...

¿Qué pasó con mi infancia y mi adolescencia y el gusto musical? Sería que todo ese tiempo estuve equivocado en mis escogencias musicales y en mi afecto por esta banda británica de rock psicodélico que dio sus primeros pasos a finales de la década de los años sesenta. La divina providencia finalmente me daría un respiro.

Mis años universitarios representaron un golpe cultural de magnitudes propias para la escala de Richter. Esta etapa conllevó la compañía de genios de

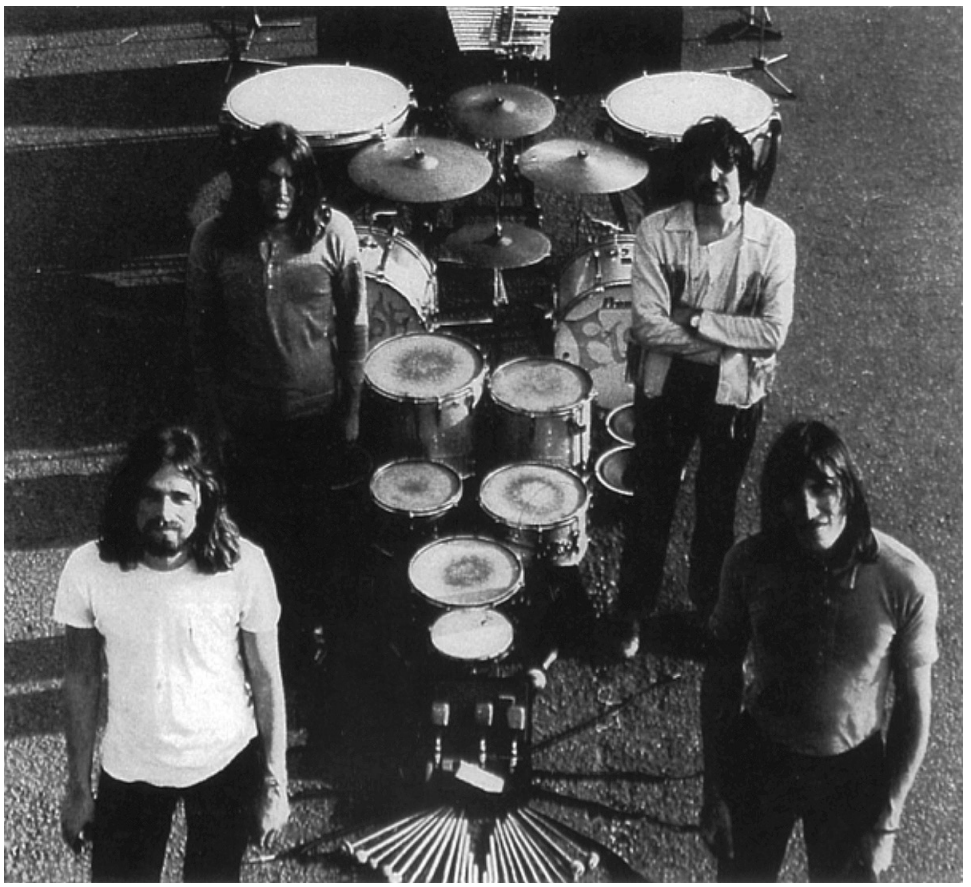
la talla de Kubrick, Lennon, Debravo, Joyce, Scorsese, y Dalí, entre otros. Aún más, significó mi reencuentro y redescubrimiento de Pink Floyd. Caminar por el pretil con "Echoes" como banda sonora o estudiar antes de un examen bajo la influencia de "Set the controls for the heart of the sun". Estas producciones culturales constituyen algunas de las memorias más evocativas de esta época en la que aprender, conocer, experimentar y vivir fueron de mis mandamientos más preciados.

¿Pero cuál la relación entre el cultivo de mis habilidades mentales y el volver, tal cual hijo pródigo, a mi cuna musical, Floyd? Considero que la respuesta de esta interrogante yace en el valor de la creación de la banda, no solo en el nivel musical, sino también temático y cultural. 


\section{Pink Floyd y su creación. Tres álbumes esenciales}

Aunque la última producción de Pink Floyd ocurrió aproximadamente hace 20 años, su legado es indiscutible. Nuevas oleadas de fans crecen con las nuevas generaciones. Sus discos se remasterizan y se dan a conocer nuevos materiales inéditos que revientan las ventas de nuevo. Asimismo, sus miembros, ya con sus carreras establecidas como solistas, regresan con espectáculos del repertorio de la banda, creaciones de una gran elaboración estética, cuya recepción es esperada con marcadas exigencias por miles de fans sedientos y conocedores en prácticamente todos los puntos cardinales del planeta. Y con mucha razón, pues la música de Floyd, como diría George Reisch, "... perteneció a un movimiento artístico-musical por encima de simple música, con el único fin de entretener las masas necesitadas de mover las caderas una vez por semana. El art-rock, movimiento

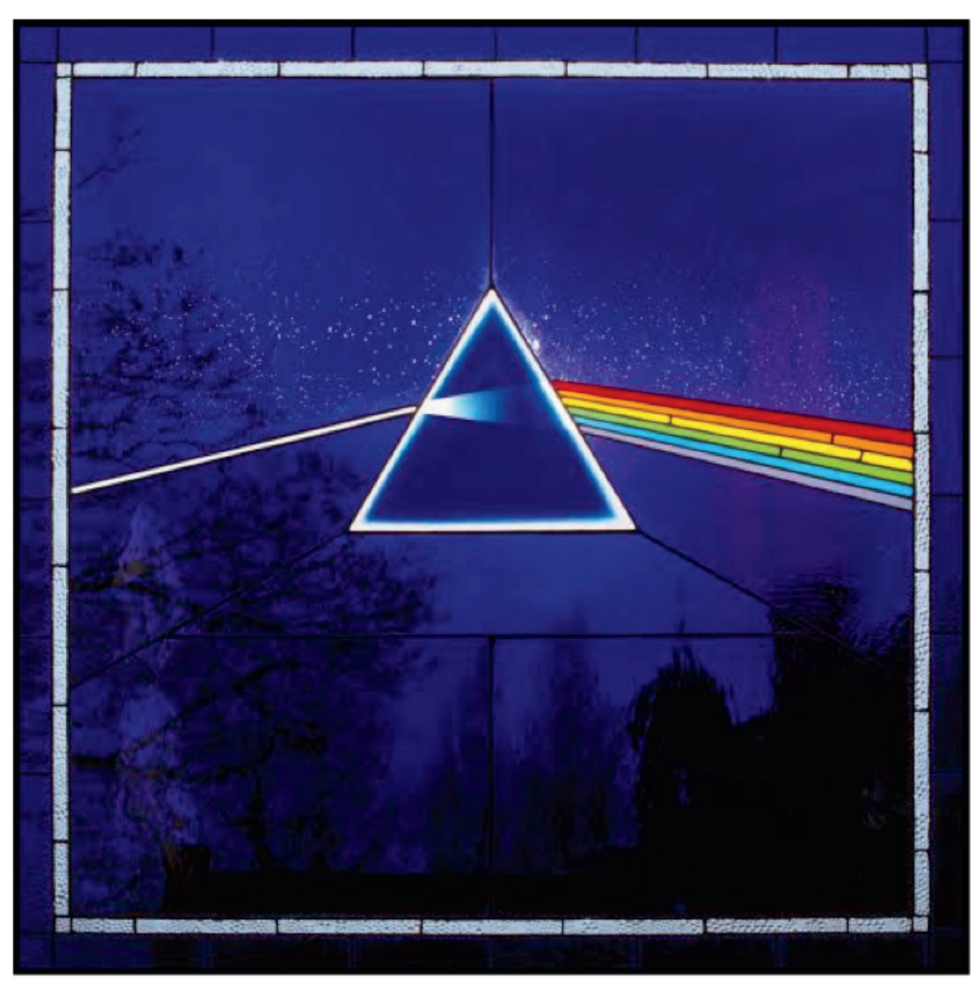
que se caracterizaba por la experimentación métrica, rítmica, melódica, armónica y temática". (2007, p. 4). ¿Esto lo hacía presuntuoso? En muchos casos sí; sin embargo, en el caso de Floyd la experimentación representó un recurso solamente si la canción así lo ameritaba. Pero aun más, en su época, así como en estos inicios del siglo XXI, la experimentación en la música de la banda constituye un grito de protesta en contra de la producción preestablecida y en masa de la industria musical. Una maquinaria con el único fin de lucrar a costa de artistas con anteojeras. En el documental Rock milestones: Pink Floyd's Wish you were here, Tony Donal hace referencia a la canción Have a cigar, en la cual se presenta el monólogo de un magnate de la industria musical, cuya caracterización es deshumanizante, un personaje interesado, egoísta, y pretencioso. Asimismo, el crítico afirma que Roger Waters, el escritor de la mayoría de letras de Floyd, estaba mordiendo la mano que le daba de comer ("bitting the hand that feeds him") al criticar de manera tan mezquina a las personas que le producían sus canciones (2005). Sin embargo, el descontento de Waters demuestra el compromiso creativo y crítico que la banda tenía con respecto a sus valores artísticos. Valores que en esa época y ahora más que nunca se encuentran en una especie de ocaso.

"Have a cigar" representa solo uno de los muchos temas críticos y transcendentales que hacen universal la obra de Floyd. Tal vez por ser británicos o por sus matices intelectuales fueron significativamente metódicos y organizados a la hora de presentar su obra. De este modo, la banda en sus diferentes álbumes explora diferentes temáticas. En el caso de The dark side of the moon, la banda quiso plasmar la vida en un mundo moderno, donde la intolerancia, la avaricia y la deshumanización constituyen los hilos que entretejen las relaciones entre las personas, su ambiente y ellos mismos. 
En este sentido, Robert Sandall apunta que "el modo en que Dark side expresa la desilusión de los jóvenes es eterno". (Longfellow, 2003, min. 9:00). Sandall se refiere a los temas de desencanto sugeridos en las letras. El mismo Roger Waters afirma que:

“... hay cosas que influyen en el individuo que determinan su visión de la existencia. Hay fuerzas que te empujan en una dirección determinada. Y éstas son algunas de ellas. Te pueden llevar a la muerte, a la locura, a la empatía a la codicia o a lo que sea" (ibíd., min. 7:00).

Dark side es un disco con temas espesos y un tanto pesimistas pero plasmado con una música brillante y armoniosa. De este modo, "Breathe" trata sobre la brevedad de la vida y las expectativas versus el vivir diario. "On the run" constituye una pieza protoelectrónica instrumental que sugiere el diario acontecer y la artificial necesidad de apurar el paso en los quehaceres cotidianos. "Time" es una burla a la condición humana, sujeta a las leyes del tiempo y la presión que conlleva "aprovecharlo". "The great gig in the sky" es otra pieza instrumental con la excepción de la voz desbordada en un solo vocal, de la cantante invitada Claire Torry - se asemeja al clímax de la muerte, otro de los temas complejos del disco y que la banda supo materializar de manera muy imaginativa, ya que ¿cómo escribir una letra y abordar un tema tan desconocido como la muerte? La solución de utilizar gritos, en lugar de letra, plasma un sentimiento, en lugar de buscar una descripción racional del tema. "Money" corresponde a una oda al materialismo, al lujo y al egoísmo que conlleva la realización monetaria por parte del ser humano. "Us and them" se centra en la eterna pelea del ser humano contra su prójimo.

Por su parte, "Brain damage" arroja ideas sugestivas sobre los parámetros de sanidad mental y locura, y como estos son relativos. Finalmente, "Eclipse" representa el exquisito cierre, el resumen de la existencia humana y del álbum, que acaba con la frase "and everything under the sun is in tune but the sun is eclipsed by the moon"; versos muy evocativos, que yuxtaponen la luz y la oscuridad para dar fin a la luz del disco en un mar de silencio.

Después del excesivo éxito de The dark side of the moon, la banda tenía un problema: superar la magnificencia de este álbum en su siguiente producción. Hubiera sido muy fácil para la banda empezar a reproducir una y otra vez la temática y el estilo musical del Dark side — que tanto elogio le había traído- en sus álbumes posteriores y decir "este es nuestro estilo y se acabó". Sin embargo, decidieron explorar otros horizontes con Wish you were here. Con música desorbitante y algo sombría, los integrantes de Floyd dedicaron cinco canciones a su amigo y excompañero de banda Syd Barrett, el cual se vio (o fue) obligado a salir del grupo debido a problemas mentales causados, en principio, por el consumo desmedido de LSD. En la década de 1960, Syd, más que un simple compañero, era la cabeza del grupo, su principal compositor. Después de su salida y de un breve estrellato, causado por los singles y el disco compuestos por Barrett, Floyd cayó en una especie de limbo, en un pseudoanonimato musical, hasta llegar a producir The dark side of the moon en 1973, cinco años después de la primera aparición de la banda en las listas de popularidad.

Durante todo ese tiempo hubo algo que los atormentó: la trágica baja de Syd y cómo ellos le debían su éxito primeramente a este, ya que fue él quien los catapultó desde un inicio. Wish you were here es la carta de despedida en la que los miembros de la banda le piden perdón y le rinden tributo a este héroe caído. Sus canciones, una por una, expresan los diferentes sentimientos con respecto a la 
tragedia. No obstante, también sugieren otros temas controversiales. Como es el caso de la mencionada, "Have a cigar " y "Welcome to the machine". Esta última presenta temas como el deshumanizante negocio musical y el sueño que se le vende a los niños acerca del éxito musical. Tony Donal lo expone de una manera clara:

El tema del álbum se aleja de la tragedia del lamento de Barrett para tratar con el aspecto industrial del negocio de la música, que sepultó al joven Syd. Es una pieza inspirada de composición de Roger Waters. El ritmo cautivador de Welcome to the machine son sonidos de maquinaria industrial procesados con sintetizadores, que se fusionan y forman el pulso rítmico de la canción. La ferocidad de las letras y el sonido incesante de la maquinaria pesada se combinan para crear una sensación de amenaza. (Rock Milestones: Pink Floyd's Wish you were here, 2005, $\min$. 41:00)

De nuevo, Floyd se adentra en las relaciones propias de la condición humana y el sistema dominante; y las imágenes sugieren, a nivel retórico, una naturaleza utilitaria y materialista. Esto lo logran con la incorporación, en la composición y en

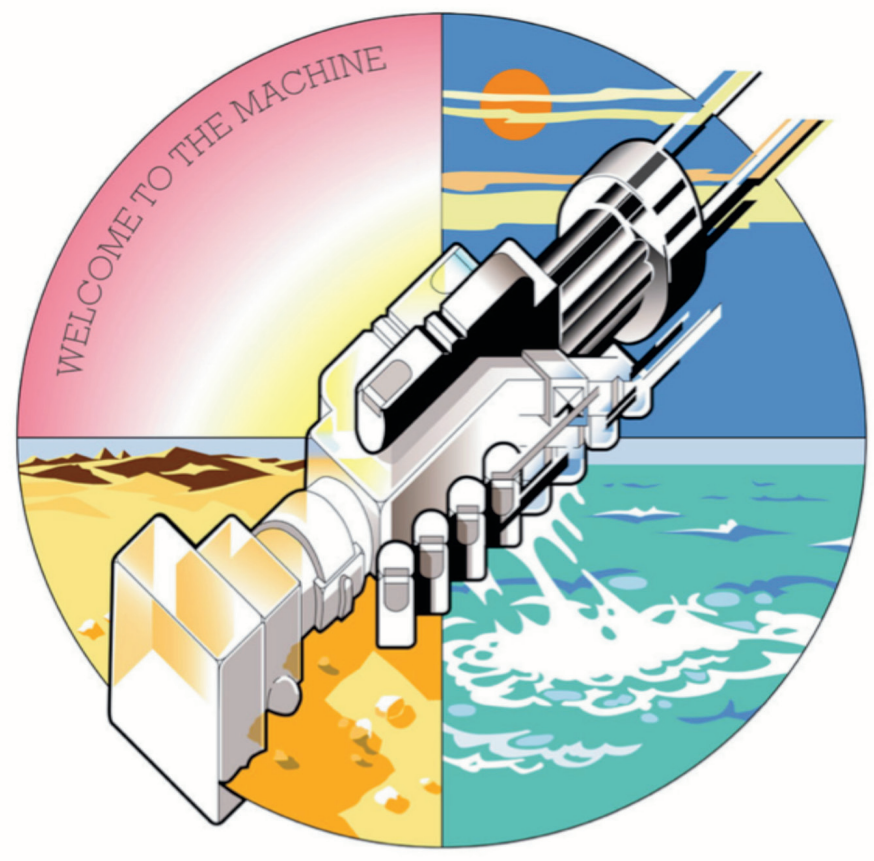
la grabación, de sonidos industriales y de maquinarias para crear este sentimiento de automatización social, donde el sistema produce sujetos con fines utilitaristas. Bajo estos supuestos, a su vez, Malcolm Dome establece:

Eso representa que vivimos en una época en que las cosas están dominadas no por el individuo, sino por las necesidades del sistema. A veces el individuo es aplastado por eso. Welcome to the machine no trata del negocio de la música, aunque pudiera verse así, sino del paso a una nueva era en la que las esperanzas, aspiraciones y logros del individuo ya no cuentan para nada. (Ibíd, 2005, min. 42: 00)

Esta pieza representa solo un ejemplo de la mirada cada vez más crítica de la banda y este disco plasma un desencanto muy humano en contra de un sistema que reprime, hostiga y lleva al individuo a extremos perniciosos.

Ya para 1979 la banda tenía bastantes problemas con respecto a las relaciones entre sus miembros. Sin embargo, un último empujón colectivo - aunque se considera que se dio más del lado de Roger Waters - resultó en otra obra maestra The wall. Pese a que el disco está acreditado mayormente como obra de Roger Waters, como letrista y compositor, se presentó como un trabajo en conjunto y bajo el nombre de la banda. El muro (como se le conoce en español) está compuesto por un álbum doble, un espectáculo nunca antes visto en el mundo de los conciertos masivos y una película. Aún más, The wall, en sus tres diferentes manifestaciones, representó un hito en la historia del rock y la música de occidente. Su historia se podría catalogar como una tragedia griega contemporánea: el relato de Pink (el personaje principal), su infancia, juventud y madurez detrás de un muro psíquico, afectivo y espiritual que lo separa de sus 


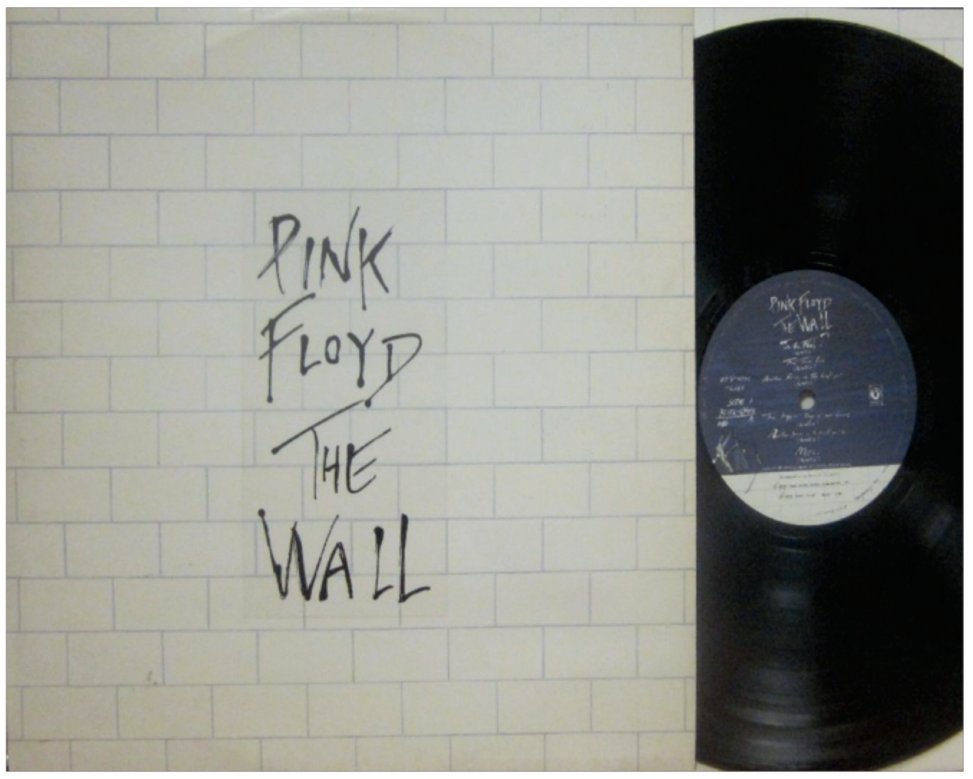

amigos, familia y otros seres humanos que forman parte de su vida. El animador que trabajó en la concepción del arte visual de The wall, Gerald Scarfe, explica que una noche Waters llegó a su casa con las cintas de los demos del disco y le explicó todo el concepto y como el muro representa aislamiento entre los seres humanos, las barreras que existen y que hacen incapaz la comunicación entre ellos (Bentley, 1999). $Y$ es que la imagen del muro constituye la alegoría perfecta para dar a entender la relación del sujeto, su medio y su sociedad: frialdad, dureza, oscuridad, aspereza y soledad. Más aún, en la historia existen factores que contribuyen a la creación de este muro ("all in all you were just bricks in the wall") como lo son un padre desaparecido en la segunda guerra mundial, una madre sobreprotectora, una educación severa The Wall. y deshumanizante, y relaciones amorosas fallidas. Waters afirma que muchos de estos factores fueron basados en acontecimientos de su vida y de sus allegados, entre ellos Syd Barrett. (ibíd.).

El muro también se enfoca en otros temas muy propios de la condición humana como la capacidad de empatía, la apatía y la intolerancia, las relaciones de poder y las instituciones sociales, la infancia y la juventud en el mundo moderno y, por supuesto, la locura (un tema muy recurrente a lo largo de la carrera de la banda). A su modo, Pink Floyd estaba realizando un análisis complejo del alma humana y de la sociedad que hemos creado en el mundo occidental. Sin embargo, lo hizo de una manera muy evocativa y conmovedora, el resultado de artistas natos plasmando sus emociones a través de su creación.

Los álbumes de Pink Floyd adquieren un valor significativo con cualidades de evidentes valores universales. Álbumes como The dark side of the moon, Wish you were here, y The wall, presentan temáticas del trajín diario que, a su vez, exponen los tipos de relaciones humanas y relaciones con el medio y el sistema. Pink Floyd parte del individuo para describir el sistema y denunciar los abusos e injusticias de este. Sus letras escudriñan los rincones más recónditos del alma humana con el único propósito de exponerla; ¿por qué?, por que así lo quisieron, no necesitaron justificación, y lo lograron de una manera tan magistral, que cada generación se enamora de sus diferentes trabajos. Mejor no lo pudo haber puesto el guitarrista y vocalista de la banda, David Gilmour: "Ias ideas que Roger exploraba gustan a cada nueva generación. No han perdido relevancia". (Longfellow, 2003, min. 1:00).

\section{Pink Floyd. Texto cultural}

Otro de los encantos de Floyd corresponde al hecho de que su trabajo fluye constantemente en la cultura. Existen muchos ejemplos de cómo su trabajo se filtra a través de la sociedad; desde los reissues de sus discos y las giras a nivel mundial de sus ex miembros - las cuales han resultado ser un éxito-, hasta 
escuchar al pulpero hablando de sus discos. Recuerdo una ocasión en la que estaba escuchando con un amigo "Shine on you crazy diamond" en la esquina fuera de mi casa cuando pasó el pulpero a la salida de su trabajo y dijo "¡ahh mirá la canción que están escuchando estos maes! Yo tengo ese acetato. Cuando quieran se llegan a mi casa y lo escuchamos". Y es que las referencias a Floyd se encuentran por doquier; basta sentarse en la Plaza de la Cultura y contar las decenas de personas llevando camisas con el arte emblemático del Dark side of the moon o de El muro. No podemos obviar los tantos tributos a Pink Floyd de bandas locales, como los de Las tortugas al Dark side; y, en el caso de los bares urbanos, los muchos afiches del arte de sus discos en las paredes o que, incluso, existe un bar llamado The wall.

Además, los temas universales de la banda son tan válidos hoy como en su época. Por ejemplo, las masacres de las escuelas en Estados Unidos, como la de Columbine en 1999 o la de Connecticut en el 2012, tienen un aire a "we don't need no education" del tema "Another brick in the wall Part II". No en el sentido de que la canción incita la violencia en centros educativos, sino que estos hechos demuestran la dimensión represiva existente en algunas circunstancias de la educación moderna y en la manera como se trata al estudiante. Sin embargo, no debemos ir fuera de nuestras fronteras para encontrar este tipo de hostilidades en las escuelas; en 2010, el caso de un joven que le disparó en la cabeza a la directora de un colegio localizado en Heredia sacudió al país. Asimismo, la xenofobia hacia nicaragüenses, colombianos, etc., las peleas entre conductores en medio de una presa o las hostilidades entre las barras de fútbol ticas aluden de manera directa al tema "Us and Them" y como Waters lo pone: "trata la cuestión fundamental de si el género humano es capaz de ser humano". (Longfellow, 2003, min. 9:00 ). Por otro lado, los temas tratados en "Welcome to the machine", así como en todo el Wish you were here, acerca de la prostitución artística y la desvalorización del artista son hoy, más que nunca, aplicables a la industria musical. La industria global exige que para ser un buen artista hay que tener

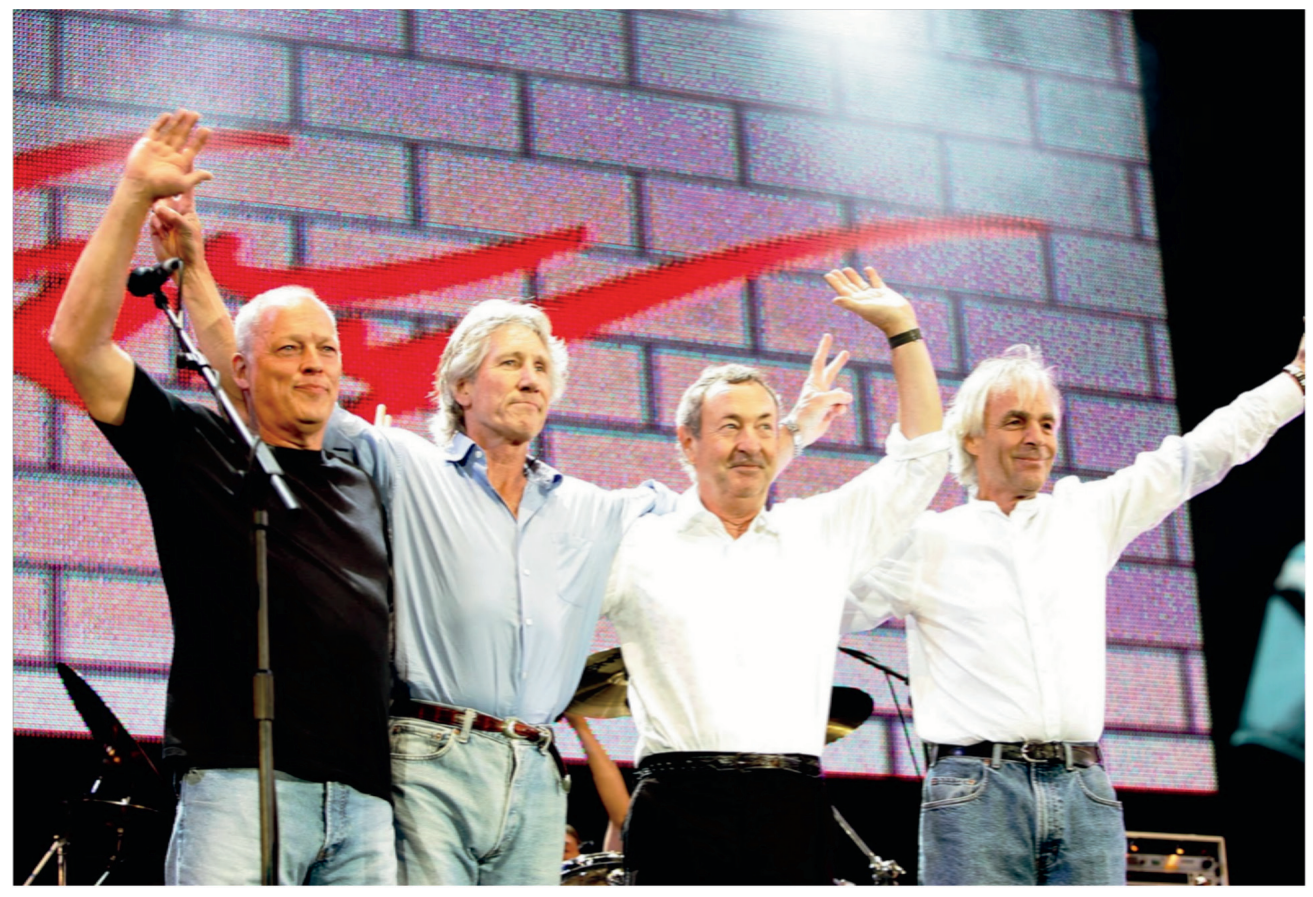


grandes atributos físicos y cualidades de baile. En el caso de nuestro país, hay una confrontación entre bandas que surgen con propuestas poco innovadoras (como Gandhi, Escats y Akasha) - como un renombrado productor tico me comentó una vez: "me fui a sacar un doctorado y cuando volví las mismas bandas nacionales estaban tocando las mismas piezas, repitiendo el patrón una y otra vez"- y un nuevo movimiento de bandas pop escazuceñas con poco contenido lírico y una abultada billetera con la cual se costean sus propias producciones, con el único propósito, pareciera, de pertenecer a la farándula tica.

\section{Good bye cruel world. Últimas palabras}

En sus letras, Floyd describía su entorno, la realidad que le rodeaba y su cultura sin saber que, al mismo tiempo, estaban describiendo toda la cultura occidental, más aún, sin saber que con sus letras estaban representando los extremos a los cuales la sociedad se ha expuesto en las últimas décadas: guerras, egoísmos, opresión, materialismo. De este modo, el trabajo de la banda tiene una cualidad profética y universal. He aquí la razón por la cual Pink Floyd seduce; sus temas cotidianos, que desnudan el alma humana y que la exponen en el lienzo de una música exquisita y evocativa son factores que cautivan desde a un académico universitario hasta a un pulpero de barrio.

\section{Bibliografía}

Bentley, B. (Director). (1999). Retrospective: Looking back at the wall: Tin Blue.

Longfellow, M. (Director). (2003). The making of the dark side of the moon: Eagle Vision.

Reisch, G. (2007). Pink Floyd and Philosophy: Careful with that Axiom, Eugene! Chicago: Open Court.

Rock Milestones: Pink Floyd's Wish You Were Here. (2005). Edgehill Publishing.

Sacido, J., \& Varela, L. (2006). Roger Waters' Poetry of The Absent Father: British Identity in Pink Floyd's The Wall. Atlantis. December, 45-58. 